\section{Effect of additional carbon source on biodegradation of linear alkylbenzene sulfonate by las-utilizing bacteria}

Kehinde I. Temitope Eniola

Department of Biological Sciences, Joseph Ayo Babalola University, Ikeji-Arakeji, Ilesa, Osun State, Nigeria

\begin{abstract}
Aerobic biodegradation of linear alkylbenzene sulfonate (LAS) by LAS-utilizing bacteria (LUB) in the presence of other sources of carbon (glucose and soluble starch) was examined. Biodegradation of LAS was monitored as primary degradation in terms of half-life $\left(\mathrm{t}^{1 / 2}\right)$ of the surfactant. Biodegradation of LAS by the individual LUB was slower in the presence of Glucose. Biodegradation of the surfactant by the various consortia of LUB was slower in the presence of the carbon sources: $t \frac{1}{2}$ increased to 3 days. The rates of biodegradation by the consortia can be ranked as: four-membered $\left(\mathrm{t}^{1} / 2=9\right.$ days $)>$ three-membered $(\mathrm{t} 1 / 2=9$ to 13 days) > two-membered consortia ( $\mathrm{t}^{1} / 2=10$ to 15 days). Generally, degradation in the presence of the carbon sources was faster with the consortia than the individual species. Degradation of the surfactant by the LUB was generally fastest in the absence of additional carbon sources. The possible role of additional carbon sources in persistence of surfactant in water bodies and the application of the observation in management of LAS-containing-effluent is suggested.
\end{abstract}

\section{Introduction}

Before 1945, synthetic detergents were virtually unknown, but gained public attention within a few years due to water pollution problems. Alkylbenzene sulfonate (ABS) replaced soap as domestic and industrial cleaning agents because of their cheapness, greater efficiency and did not cause precipitation of calcium salts in areas with hard water. ${ }^{1} \mathrm{ABS}$ (hard detergent) did not readily breakdown in sewage treatment processes giving rise to environmental complications: problems of toxicity to aquatic organisms and aestheticsundesirable presence of foam scum on water. ${ }^{2}$ ABS was subsequently banned and gradually replaced in the 1960 s by linear alkylbenzene sulfonate (LAS), which is readily biodegradable. $^{3}$

The degradation of surfactant is of great interest, and remains a factor in the acceptability or rejection of surfactants. Aerobic biodegradation of LAS can be divided into primary degradation and ultimate degradation. Primary degradation involves the disappearance of the parent molecule and loss of interfacial activity. It is initiated by alkylsulfatase whose presence is suggested to be synonymous with ability to accomplish mineralization of LAS. ${ }^{4}$ Studies have shown that primary degradation occurs during the initial reactions in the metabolic pathway. Primary degradation is transformation induced by microorganisms resulting in the production of short chain homologues: sulphophenyl carboxylates (SPCs). ${ }^{5}$

Ultimate degradation is the cleavage of the aromatic ring and complete conversion of LAS and SPCs to water, $\mathrm{CO}_{2}$, inorganic sulphates and biomass. Ultimate degradation of LAS involves the action of two or three tiers of bacteria. ${ }^{6}$ The first tier organisms possess enzymes for $\omega$ - and $\beta$-oxidation of the alkyl chains. The second tier organisms convert the resultant long chain SPCs (lc-SPCs) by further $\beta$-oxidation of the alkyl chain, forming short chains SPCs (sc-SPCs). The third tier organisms mineralize the sc-SPCs via 4sulfocatechol and ortho ring cleavage. ${ }^{3,5}$ The opening of the aromatic ring is the rate-limiting step for ultimate degradation of LAS.?

Most studies on biodegradation of LAS have considered situation in which the surfactant is present as sole carbon source. This is a rare occurrence because the aquatic environment, in particular serves as receptacle for a large number of pollutants; no single pollutant exists alone in the environment. Some materials have simple structures that make them more prone to microbial attack than other more complex molecules. Also some organisms have preference for some types of carbon substrates. In this study, the biodegradation of LAS in the presence of other utilizable carbon source is examined. Individual and consortia bacteria were examined in their ability to degrade the surfactant in the presence of glucose and soluble starch as additional sources of carbon. Degradation of LAS was monitored as half-life ( $\left.\mathrm{t}^{1 / 2}\right)$, which is the time it takes for microbes to breakdown half the amount of a chemical in water.

\section{Materials and Methods}

\section{Selection of organims}

Alcaligenes odorans, Citrobacter diversus, Micrococcus luteus and Pseudomomas putida previously isolated from detergent-effluent polluted stream ${ }^{8}$ were selected from among the LAS-tolerant bacteria. The bacterial isolates
Correspondence: Kehinde I. Temitope Eniola, Department of Biological Sciences, Joseph Ayo Babalola University, Ikeji-Arakeji, P. M. B. 5006, Ilesa, Osun State, Nigeria.

E-mail: kennyeniola@gmail.com

Key words: linear alkylbenzene sulfonate, aerobic degradation, consortia, carbon source, starch, glucose.

Received for publication: 23 May 2011. Accepted for publication: 5 August 2011.

This work is licensed under a Creative Commons Attribution 3.0 License (by-nc 3.0).

(C) Copyright K.I.T. Eniola, 2011

Licensee PAGEPress, Italy

Journal of Xenobiotics 2011; 1:e2

doi:10.4081/xeno.2011.e2

were screened for ability to degrade LAS by plating them separately on Mineral salt medium containing LAS as sole carbon source. Organisms with degradative ability were then selected and standardized as 0.5 McFarland standard $\left(10^{8} \mathrm{cell} / \mathrm{mL}\right)$ and were used as inoculum in degradation study.

\section{Degradation studies}

LAS mineral broth was prepared by dissolving anhydrous LAS (1\% w/v) in mineral salt medium $^{9}$ glucose-supplemented and soluble starch-supplemented LAS broths were then prepared by dissolving $1 \%(\mathrm{w} / \mathrm{v})$ of the carbon source (glucose and starch) in the broth. Flasks containing $300 \mathrm{~mL}$ of medium was inoculated with $10 \mathrm{~mL}$ broth culture of standardized selected organisms as individual pure cultures and various consortia of two, three and four members. The inoculated media were incubated on an orbital shaker (100 rpm) at room temperature $\left(28 \pm 2^{\circ} \mathrm{C}\right)$.

Aliquots $(10 \mathrm{~mL})$ of the resulting cultures were withdrawn daily and the concentration of surfactant determined using the Hyamine titration method..$^{10}$ Biodegradation was monitored daily as primary degradation in terms of half-life of the surfactant. The half-life is indicated by $50 \%$ reduction in initial concentration of surfactant. An un-inoculated medium treated in the same way served as control. Data obtained were analyzed statistically using the ANOVA.

\section{Results}

The effect of the additional carbon sources on the degradation of the surfactant by the organisms is shown on Figures 1-3. It shows that the rate of degradation was fastest in all cases when there was no other source of car- 
bon. The presence of glucose increased $t^{1} / 2$ by 3 days: Pseudomomas putida; 2 days: Citrobacter diversus; 3 day: Micrococcus luteus and 3 days: Alcaligenes odorans. Soluble starch increased t $1 \frac{2}{2}$ by 2 days: Pseudomomas putida; 1 day: Citrobacter diversus; 2 day: Micrococcus luteus and 1 days: Alcaligenes odorans (Figure 1). In the case of the two-membered consortia of organisms, the presence of the additional carbon sources increased $t 12$ by 2 days in all cases except for the consortium of Alcaligenes odorans and Citrobacter diversus, in which case the presence of starch increased $t \frac{1}{2}$ by 1 day (Figure 2).

Among the three-membered consortia, the presence of glucose increased $t 1 / 2$ by between 4 days (Citrobacter diversus $M$. luteus and $P$. putida) and 2 day (A. odorans Citrobacter diversus and P. putida; A. odorans, M. luteus and $P$. putida). In the case of soluble starch; $\mathrm{t}^{1 / 2}$ increased by between 3 days (A. odorans Citrobacter diversus and $P$. putida; Citrobacter diversus M. luteus and $P$. putida) and 2 days ( $A$. odorans, $C$. diversus and $M$. luteus; $A$. odorans, $M$. luteus and $P$. putida). The carbon sources increased $t^{1} / 2$ by 2 days each in the case of the four-membered consortium (Figure 3). The rates of degradation by the consortia can be ranked as: four-membered $(\mathrm{t} 1 / 2=8$ days) $>$ three-membered $\left(\mathrm{t}^{1} / 2=8-13\right.$ days $)>$ two-membered ( $\mathrm{t}^{1} / 2=10-15$ days) consortia. Generally, biodegradation of LAS was slowest in the presence of glucose and fastest when LAS was sole carbon sources were absent. There was no significant difference in the rates $\left(t^{1 / 2}\right)$ of degradation by the selected organisms and their $(\mathrm{P}<0.05)$.

\section{Discussion}

The difference in rate of degradation by pure cultures and consortia of the organisms in the presence of additional carbon sources suggest the influence of availability of alternative carbon source. This is attributable to the preferentially selection of easily utilizable substrates by microorganisms over other substrates. ${ }^{11}$ The inhibitory effect of carbon sources on biodegradation of styrene has been reported. ${ }^{12,13}$ The effect of the presence of additional carbon sources observed in this study is consistent with the higher anaerobic degradation of LAS in the absence of additional sources of carbon that has been observed. ${ }^{14}$ Similarly, sludge acclimatized to the degradation of phenol showed an initial preference for easily degradable co-substrates such as glucose with only a slow concomitant assimilation of phenol. ${ }^{15}$ However, assimilation of phenol increased rapidly after the co-substrates were depleted and phenol was preferentially taken in the presence of a less easily degradable co- substrate. ${ }^{16}$

The observed effect partly explains the persistence of the surfactant in water bodies which was observed by Eniola and Olayemi. ${ }^{17}$ The water bodies usually serve as receptacle for a large number of pollutants, many of which are simpler in structure compared to the LAS. The presence of more readily utilizable molecules could create a situation in which the surfactant is only co-metabolized while other molecules are used as source of carbon. Co-metabolism is defined as the transforma- tion of a non-growth substrate in the obligate presence of a growth substrate or other transformable substance. ${ }^{18}$ Co-metabolism could result in intermediate products that are recalcitrant or more toxic than LAS. ${ }^{19}$

The slower rate of degradation of the surfactant in the presence of glucose is because glucose is a substrate that is readily used by most organisms. It can be readily taken into the cell by the group translocation system as against the LAS that would need to be broken first. Rate regulation would be informed by the bal-

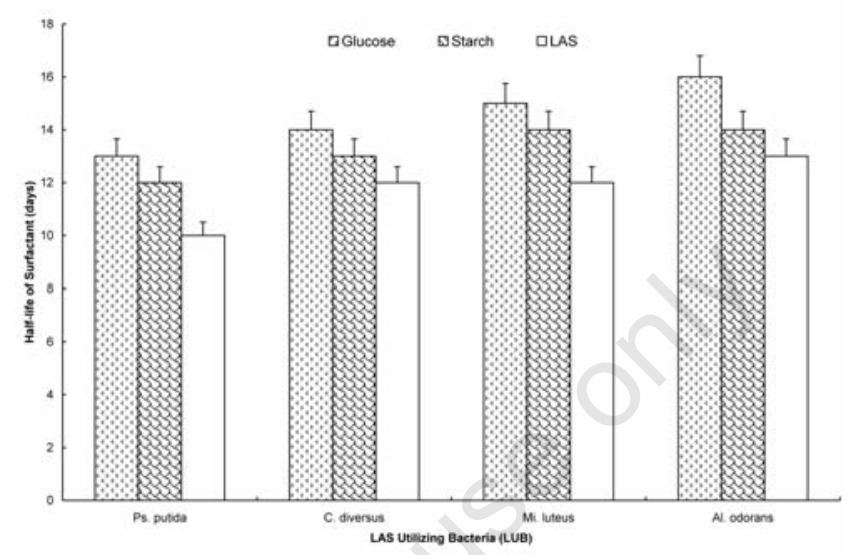

Figure 1. Biodegradation of LAS by individual LAS-utilizing bacteria in the presence of glucose and starch.

Ps. Putida, Pseudomomas putida; C. Diversus, Citrobacter diversus; MI luteus, Micrococcus luteus; Al. odorans, Alcaligenes odorans.

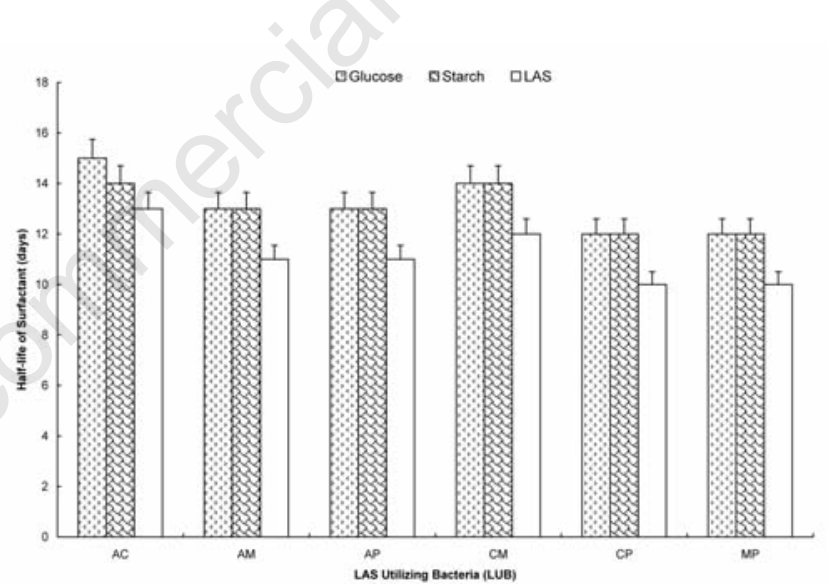

Figure 2. Biodegradation of LAS by two-membered consortia of LAS-utilizing bacteria in the presence of glucose and starch.

$A C$, $A$. odorans and $C$. diversus; $A M$, A. odorans M. luteus; $A P$, Alcaligenes odorans $P$. putida; $C M$, Citrobacter diversus M. luteus; $C P$ Citrobacter diversus $P$; MP M. luteus P. putida.

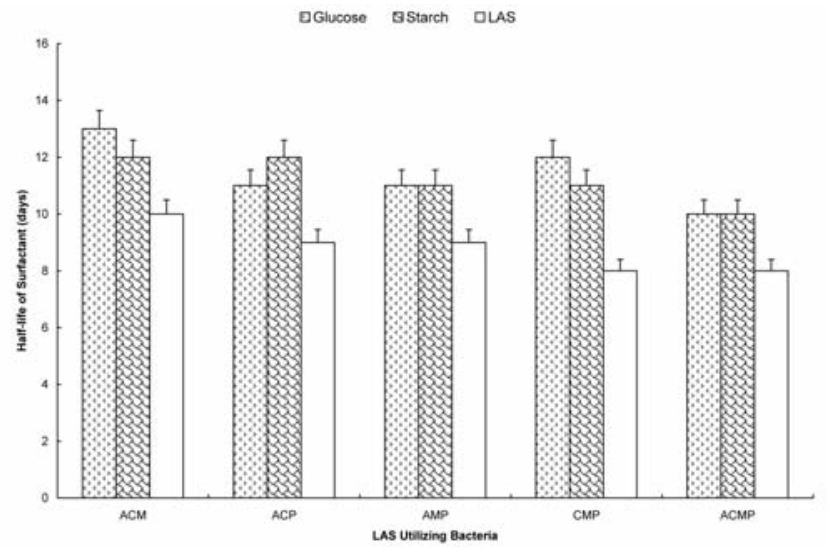

Figure 3. Biodegradation of LAS by consortia of LASutilizing bacteria in the presence of glucose and starch.

ACM, A odorans, $C$. diversus and M. luteus; ACP.A. odorans Citrobacter diversus and P. putida; AMP, A. odorans, M. luteus and P. putida; CMP, Citrobacter diversus M. luteus and P. putida; ACMP, A. odorans, C. diversus, M. luteus and P. putida.. 
ance of equilibrium between substrate and product; hence the presence of glucose is likely to tilt the reaction away from the breakdown of LAS. The transformation products of LAS are feed into the central metabolic pathway (Krebs cycle and glyoxylate cycle) present in bacteria. $^{20}$

The presence of additional sources of carbon could serve, on the long run, as a means of building up biomass for eventual degradation of the LAS. Yediler et al. ${ }^{21}$ reported that a direct correlation between the rate of primary degradation and the initial bacterial population. Dentel et al. ${ }^{22}$ similarly associated the complete mineralization of LAS to the number of organisms present. This is perhaps part of the reason why there is no statistical difference $(\mathrm{P}<0.05)$ in the rates of degradation of the surfactant by pure cultures and their consortia.

\section{Conclusions}

Generally, biodegradation of LAS was slowest in the presence of glucose and fastest when LAS was sole carbon sources were absent. The presence of the additional carbon source slowed down the degradation of LAS by the organisms. The consortia also degraded LAS at a faster rate than the individual pure culture. This study provides information that can be useful in the operating Waste treatment plant (WTP) for LAS-containing effluents. For such WTP, it is important to use consortia of organisms; in addition wastes that contain easily degradable carbon sources should not be pooled with LAS-containing wastes.

\section{References}

1. Abel PD. Detergents. Water Pollution Biology (2nd Edition). Taylor and Francis Ltd.: London; 2002. pp. 63-65.

2. Houston CA. Detergents: Changing Expectation, Content. Inform 1997;8:92838.

3. WHO. International Programme on
Chemical Safety. Environmental health criteria 169. Linear alkylbenzene sulfonates and related compounds. World Health Organization. Geneva, Switzerland; 1996.

4. Anderson DJ, Day MJ, Russell NJ, White GF. Temporal and geographical distribution of epilitic sodium dodecyl sulfatesdegrading bacteria in a polluted South Wales river. Appl Environ Microbiol 1988; 54:555-60.

5. Cook AM, Hrsak D. The complete degradation of LAS is becoming better understood with pure cultures of bacteria. The CLER Review 2000;6:46-53.

6. Dong W, Eichhorn P, Radajewski S, et al. Parvibaculum lavamentivorans converts linear alkylbenzenesulphonate to sulphophenylcarboxylates, alpha, betaunsaturated sulphophenylcarboxylates and sulphophenyldicarboxylates, which are degraded in communities. J Appl Microbiol 2004;96:630-40.

7. Cavalli L, Cassani G, Maraschin C. Structural Elucidation of Linear Alkylbenzene Sulfonate (LAS) biodegradation Intermediates. The CLER Review 1996;2:4-13.

8. Eniola KIT, Olayemi AB. Linear Alkylbenzene Sulfonate tolerance in bacteria isolated from sediment of tropical water bodies polluted with detergents. Rev Biol Trop 2008;56:1595-601.

9. Ogunseitan OA. Removal of caffeine in sewage by Pseudomonas putida: Implication for water pollution index. World $\mathrm{J}$ Microbiol Biotechnol 1996;12:251-6.

10. Mettler Toledo. Turbidimetric titration: Determination of anionic surfactants / M603. 2011. Available from: http:/it.mt. com/it/it/home/supportive_content/application_editorials.M603.titrationEd.html

11. Clarke PH. Microbiology and Pollution: The biodegrdation of Natural and synthetic compounds. Phil Transf R Soc Lond 1980;290:355-67.

12. Holtel A, Marques S, Mohler I, et al. Carbon source dependent inhibition of xyl operon expression of Pseudomonas putida TOL plasmid. J Bacteriol 1994;176:1773-6.
13. O’Connor K, Buckley CM, Hartmans S, Dobson AD. Possible regulatory role for non aromatic carbon source in styrene degradation by Pseudomonas putida CA-3. Appl Environ Microbiol 1995;61:544-8.

14. Sanz JL, Culubret E, de Ferrer J, et al. Anaerobic degradation of linear alkylbenzene sulfonate (LAS) in upflow anaerobic sludge blanket (USAB). Biodegradation 2003;14:57-64.

15. Bajaj M, Callert C, Winter J. Effect of CoSubstrates on Aerobic Phenol Degradation by Acclimatized and Non-acclimatized Enrichment Cultures. Eng Life Sci 2008;8:125-31.

16. Shimp R, Pfeander FK. Influence of easily degradable naturally occurring carbon substrate on biodegradation of monosubstituted phenols by aquatic bacteria. Appl Environ Microbiol 1985;49:394-401.

17. Eniola KIT, Olayemi AB. Utilization of detergent surfactant by bacteria isolated from freshwater bodies. Nig J Microbiol 2000;14:49-53.

18. Bollag WB, Bollag J. Biodegradation. Encyclopedia of Microbiology. Vol. 1. Academic Press: London, UK; 1992. pp. 269-276.

19. Hardman DJ. Microbial Control of Environmental Pollution: The use of Genetic Techniques to Engineer Organisms with Novel Catalytic Capabilities. In: Environmental Biotechnology. Forster CF, John Wase DA (eds.). Ellis Horwood Ltd.: London, England; 1989. pp. 295-317.

20. Schoberl P. Basic principles of LAS biodegradation. Tenside Deterg 1989;26: 86-94.

21. Yediler A, Zhang Y, Cai JP, Korte F. Effect of the microbial population size on the degradation of linear alkylbenzene sulfonate in lake water. Chemosphere 1989;18:1589-97.

22. Dentel SK, Allen HE, Srinivasarao C, Divincenzo J. Effects of surfactants on sludge dewatering and pollutant fate. Third year completion report project number 06. Water Resources Center. University of Delaware. Delaware, USA. 1993. 